\section{A Cultured Greigite-Producing Magnetotactic Bacterium in a Novel Group of Sulfate-Reducing Bacteria}

Christopher T. Lefèvre, Nicolas Menguy, Fernanda Abreu, Ulysses Lins, Mihály Pósfai, Tanya Prozorov, David Pignol, Richard B. Frankel, Dennis A. Bazylinski

Magnetotactic bacteria contain magnetosomes-intracellular, membrane-bounded, magnetic nanocrystals of magnetite $\left(\mathrm{Fe}_{3} \mathrm{O}_{4}\right)$ or greigite $\left(\mathrm{Fe}_{3} \mathrm{~S}_{4}\right)$-that cause the bacteria to swim along geomagnetic field lines. We isolated a greigite-producing magnetotactic bacterium from a brackish spring in Death Valley National Park, California, USA, strain BW-1, that is able to biomineralize greigite and magnetite depending on culture conditions. A phylogenetic comparison of BW-1 and similar uncultured greigite- and/or magnetite-producing magnetotactic bacteria from freshwater to hypersaline habitats shows that these organisms represent a previously unknown group of sulfate-reducing bacteria in the Deltaproteobacteria. Genomic analysis of BW-1 reveals the presence of two different magnetosome gene clusters, suggesting that one may be responsible for greigite biomineralization and the other for magnetite.

$\mathrm{S}$ everal different groups of magnetotactic bacteria biomineralize magnetic mineral nanocrystals of magnetite $\left(\mathrm{Fe}_{3} \mathrm{O}_{4}\right)$ and greigite $\left(\mathrm{Fe}_{3} \mathrm{~S}_{4}\right)$ through fundamentally different mechanisms (1). A number of magnetite-producing magnetotactic bacteria have been isolated and their genomes sequenced, revealing details about magnetite biomineralization at the molecular level (2-4), but no greigite-producing bacteria have been isolated and grown in axenic culture. There are two known morphological types of greigite-producers: a group of multicellular prokaryotes ["many-celled magnetotactic prokaryotes" (MMPs)], and a group of large rod-shaped bacteria (5). Although environmental studies revealed a good deal of information regarding MMPs (6-11), little is known about the large rod-shaped group except that some appear to produce magnetite as well as greigite in the same cell (12-14). One report describes a putative large, greigite-producing rod belonging to the Gammaproteobacteria (8), although its affiliation with this group is uncertain (15).

Here, we report a comprehensive phylogenetic analysis of large, rod-shaped, greigite- and/or magnetite-producing magnetotactic bacteria and the isolation and characterization of one of these microorganisms, strain BW-1, from a brackish spring at Badwater Basin, Death Valley National Park, California, USA. We collected water and sediment samples from numerous freshwater, brackish, and hypersaline aquatic environments located in the southwestern United States (table S1) (16).
Although the magnetotactic bacterial populations in the samples were not homogeneous, the large rods were often the dominant magnetotactic bacterium present in the samples, as determined with microscopy by using the hanging drop technique (movie S1) (17). To obtain cells for analyses, magnetotactic bacteria were first magnetically enriched in sample bottles (18) and then purified using the magnetic racetrack procedure (19). After purification, cells were used to inoculate a variety of different growth media for electron microscopy, phylogenetic analysis, and fluorescence in situ hybridization.

We observed a wide range of large magnetotactic rods collected from different freshwater and saline environments (Fig. 1). In all cases, cells possessed a single polar flagellum (Fig. 1, A and D). Some cells contained mainly greigite (Fig. 1, A to C) or magnetite (Fig. 1, D to F), whereas others produced both minerals (Fig. 1, G to I, and table $\mathrm{S} 1$ ), as determined by means of selectedarea electron diffraction (SAED) in the electron microscope. Although the morphologies of the greigite crystals were generally pleomorphic, in all cases the magnetite crystals were bullet- or arrowhead-shaped [elongated anisotropic (20)] (Fig. 1, E, F, H, and I). Using bacterial-specific primers for the $16 S$ ribosomal RNA (rRNA)
Fig. 1. Transmission electron microscope (TEM) images of uncultured, large, greigite- and/or magnetite-producing, rod-shaped bacteria. (A and $\mathbf{B}$ ) TEM images of cells collected from a spring at ambient temperature in the Great Boiling Springs geothermal field in Gerlach, Nevada, USA. (C) High-magnification TEM image of greigite crystals from the cell shown in (B). (D) TEM image of a cell collected from Lake Mead, Nevada, USA. (E) Highmagnification TEM image of magnetosomes in cell shown in (D). Magnetosome crystals in this cell are bullet-shaped magnetite. (F) TEM image of cell collected from Bridgeport Reservoir, Bridgeport, California, USA, showing double chain of bullet-shaped magnetite crystals. (G) TEM image of a cell collected from a freshwater pond close to Zion National Park, Utah, USA. (H and I) High-magnification TEM images of magnetosomes in (G) showing greigite and bulletshaped magnetite crystals aligned in the same chains.
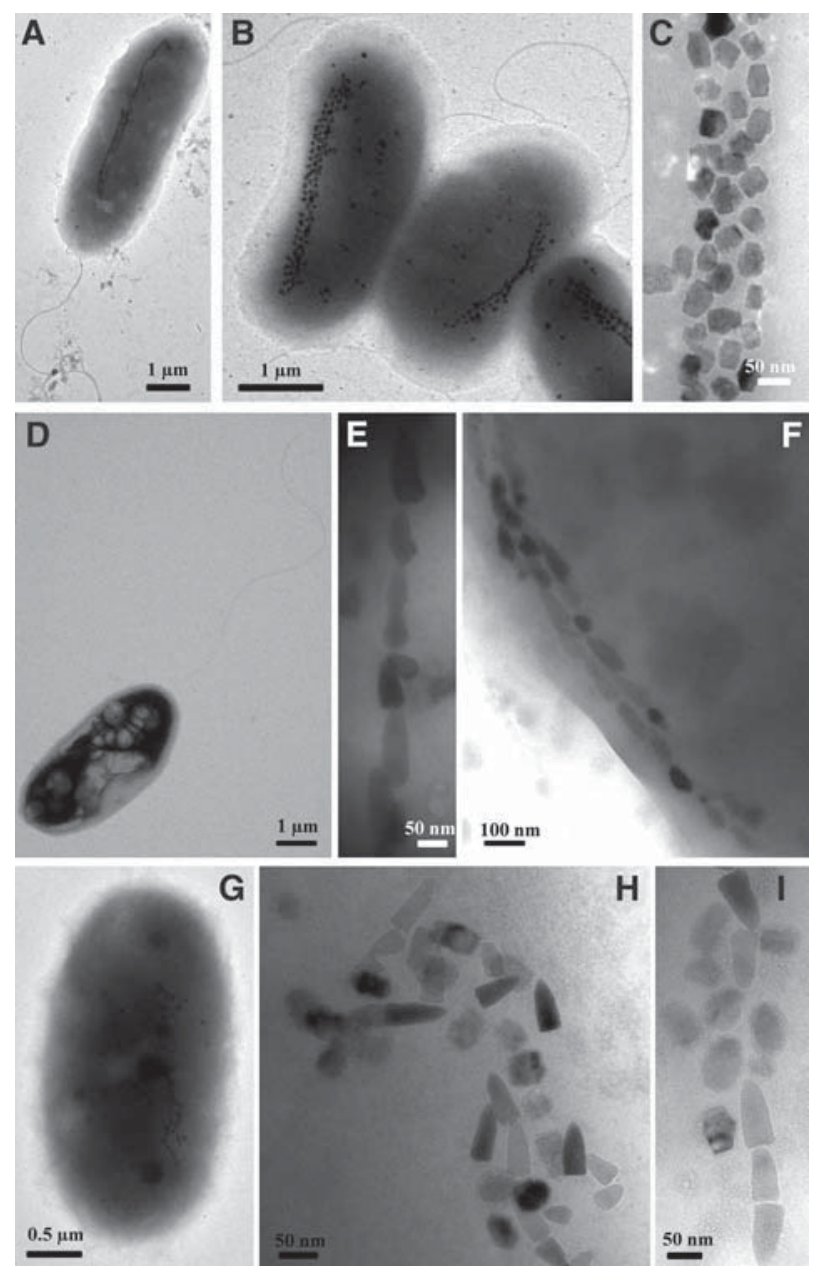
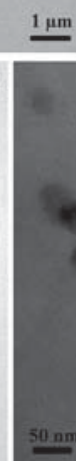
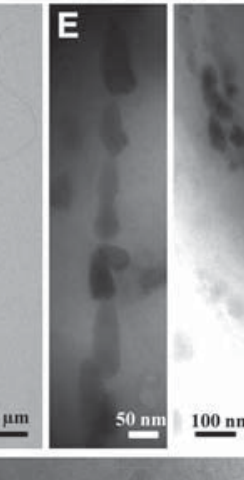

\section{.}


Fig. 2. Fluorescent in situ hybridization (FISH) of large, greigite- and/or magnetite-producing, rod-shaped magnetotactic bacteria (LGRs) to the specific oligonucleotide rRNA probe (LGRp). (A) FISH of LGR cells collected from Badwater Basin, Death Valley National Park, California, USA. (B) FISH of LGR cells collected from Rogers Spring at the Lake Mead National Recreation Area, Nevada, USA. (Left) Differential interference contrast (DIC) images of magnetically enriched cells from water and sediment samples. (Middle) fluorescence microscope images of the same cells stained with 4,6-diamidino2-phenylindole (DAPI).
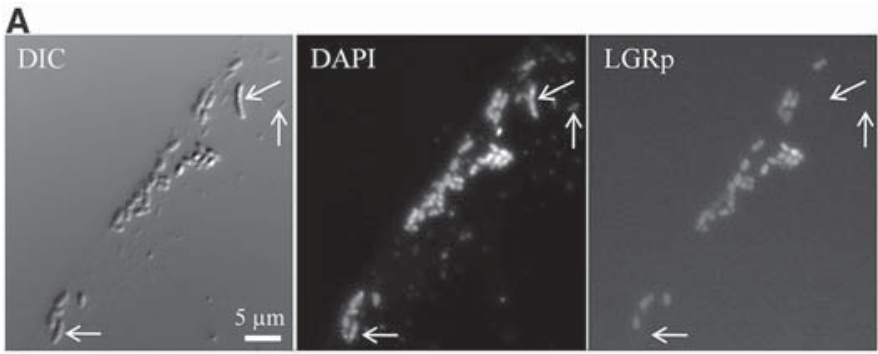

B
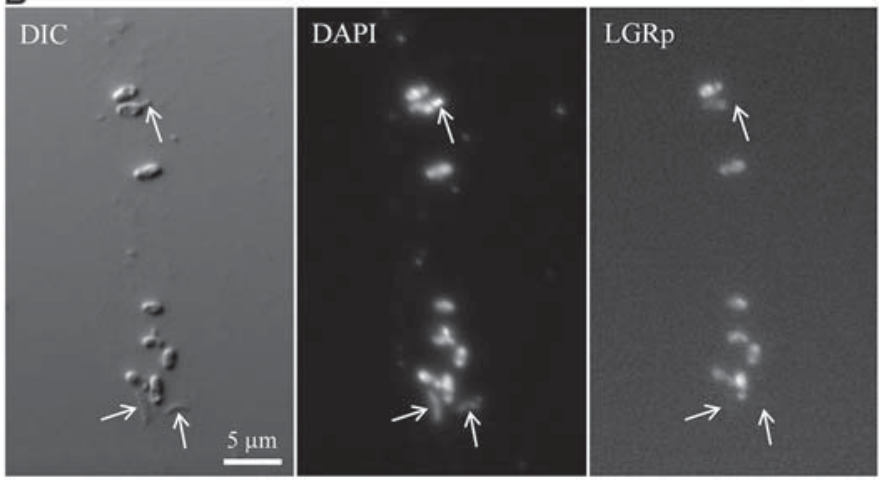

gene and polymerase chain reaction (21), we obtained 25 nearly complete $16 S$ rRNA gene sequences from these rod-shaped organisms collected from 12 different sites. Using specific oligonucleotide probes designed from these sequences and in situ fluorescent hybridization, we authenticated the $16 S$ rRNA gene sequences obtained from these organisms (Fig. 2).

Phylogenetic analysis of the $16 \mathrm{~S}$ rRNA gene sequences from the large rod-shaped magnetotactic bacteria show that these organisms form a clade within the sulfate-reducing bacteria in the Deltaproteobacteria class of the Proteobacteria phylum that does not contain any other known cultured bacteria (Fig. 3). This clade appears to consist of at least two smaller groups, each constituting at least two genera based on $16 \mathrm{~S}$ rRNA divergence. We were unable to correlate the separation of these subgroups with cell morphology, environmental parameters of the organisms' habitat such as salinity, or composition of magnetosome crystals.

Our phylogenetic results appear to contradict the recent assignment of an uncultured, putative, greigite-producing rod to the Gammaproteobacteria (8); however, the group-specific $23 S \mathrm{RNA}$ targeted probe GAM42a for this bacterium (22) does not allow for the unambiguous binding of any gammaproteobacterial-specific sequences
Fig. 3. Phylogenetic tree, based on $16 S$ rRNA gene sequences, showing the phylogenetic position of LGRs in the Deltaproteobacteria class. Bootstrap values at nodes are percentages of 1000 replicates. 165 rRNA gene sequences of the uncultured magnetotactic bacteria Candidatus Thermomagnetovibrio paiutensis (28) and $\mathrm{Ca}$. Magnetoovum mohavensis (29) of the Nitrospirae phylum were used to root the tree. GenBank accession nos. are given in parentheses. Bar represents $2 \%$ sequence divergence. Letters in sequence designations indicate sampling site listed in table S1, and numbers following represent clone number. BP, Bridgeport Reservoir; LK, Lake Mead; NML, freshwater pond near Mono Lake; ZZ, Lake Tuendae; ZP, freshwater pond near Zion National Park; ZBP, Zuma Beach; RG, Rogers Spring; GL, pools at Great Boiling Springs; PL, Pyramid Lake; SS, Salton Sea; SS-2c, lagoon at Salton Sea; BB, Badwater Basin; and WH, Salt Pond. Details and exact coordinates are provided in table S1. BW-1 refers to the cultured LGR described in the text.

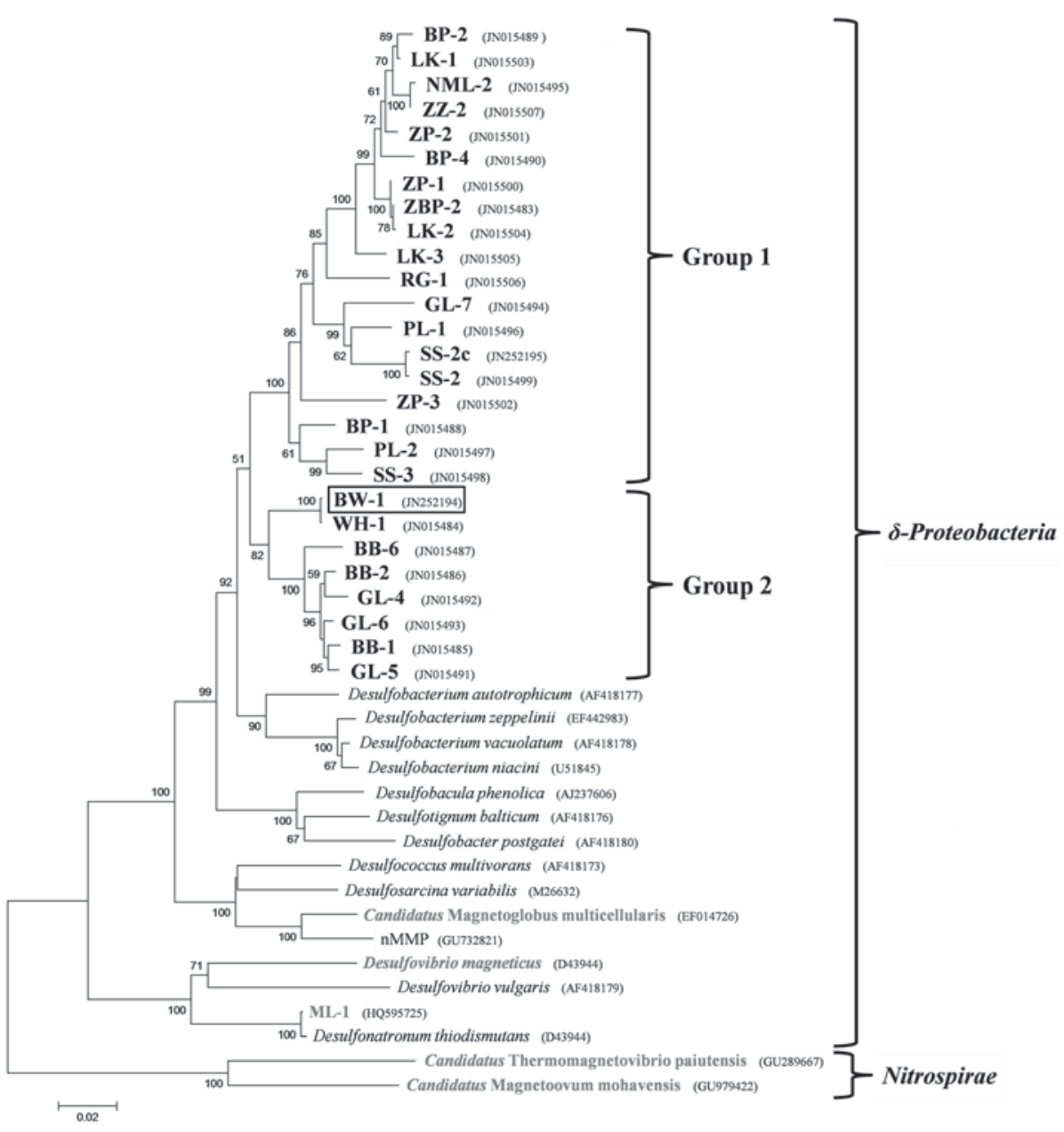


to this bacterium (15). The recent discovery of magnetite-producing rods that belong to the Gammaproteobacteria and are found in the same habitats as rod-shaped greigite-producers (18) might also explain this discrepancy.

Magnetically purified, large, rod-shaped, magnetotactic bacteria from several sites were inoculated into a variety of growth media. Growth of some of these organisms was observed in an anaerobic, complex, liquid growth medium for the enrichment of heterotrophic sulfate-reducing bacteria. Through three successive rounds of dilution to extinction in this medium, two pure cultures were obtained: strain BW-1 from Badwater Basin and strain SS-2 from the Salton Sea (California, USA). Both strains phylogenetically lie within the clade of the uncultured large rods in the Deltaproteobacteria class (Fig. 3). Strain SS-2 appeared to only biomineralize magnetite under our culture conditions.

In culture, BW-1 produces one or two loose chains of magnetosomes that contain greigite and/or magnetite, as determined through a combination of elemental mapping by using energyfiltered imaging (figs. S1 and S2) and electron diffraction (Fig. 4, A to C, and figs. S2C and S3B). Magnetosome mineral composition correlated with the concentration of hydrogen sulfide formed during growth. For example, when sulfide was allowed to accumulate in the growth medium ( $>0.3 \mathrm{mM}$ sulfide) most magnetosomes contained greigite (Fig. 4, and figs. S1 and S2).
When the headspace of the cultures was purged every other day with oxygen-free argon gas so as to decrease the concentration of hydrogen sulfide in the cultures $(<0.3 \mathrm{mM})$, cells contained chains of bullet-shaped, magnetite-containing magnetosomes (fig. S3). Thus, whether greigite and/or magnetite are produced in the magnetosomes of these organisms is affected by external environmental conditions such as hydrogen sulfide concentration and/or redox potential. This finding is consistent with observations on uncultured rodshaped, greigite-producing magnetotactic bacteria in a chemically stratified, oxygen/sulfide inverse gradient system (13).

Magnetite crystals produced by BW-1 were consistently bullet-shaped, whereas greigite crystals had irregular outlines and lacked a well-defined crystal habit (Fig. 4, B and C). Thin sections of greigite magnetosomes reveal an electron-dense layer surrounding the crystal that is consistent with the presence of a magnetosome membrane (Fig. 4, E and F), which has also been observed in greigite magnetosomes of the MMP Candidatus Magnetoglobus multicellularis (23).

Our sampling effort demonstrates that greigiteproducing magnetotactic bacteria are not confined to marine habitats as previously thought (8). Although several of these organisms collected from different sites appeared to only contain magnetite, it seems likely that all can biomineralize greigite under the appropriate conditions (such as when sulfate is present as the terminal electron
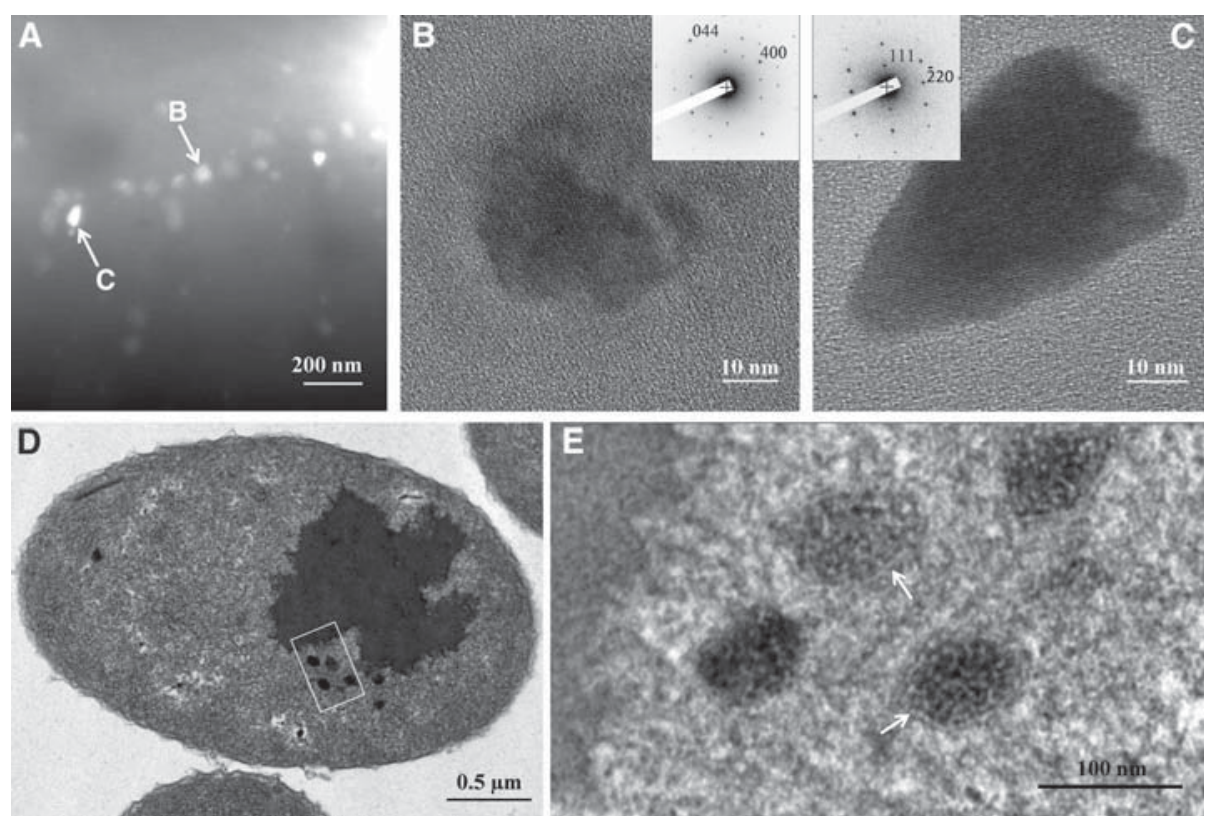

Fig. 4. TEM images of strain BW-1. (A) Darkfield scanning TEM image of a magnetosome chain containing both greigite (labeled B) and magnetite (labeled C). (B) High-magnification TEM image of greigite crystal labeled in (A). (Inset) SAED of crystal viewed along the [0 -111$]$ zone axis. Pattern is consistent with greigite. (C) High-magnification TEM image of magnetite crystal labeled in (A). (Inset) SAED pattern of crystal viewed along the [ $-1-12$ 2] zone axis. (D) TEM image of a stained thin-section of a cell of BW-1 showing several magnetosomes aligned in the cell. Dark, intracellular, electron-dense mass represents large cell inclusion that is also visible by use of light microscopy. (E) High-magnification TEM image of magnetosomes in (D) showing that an electron-dense layer surrounds the greigite crystals, suggesting the presence of a magnetosome membrane. acceptor and is reduced to sulfide), on the basis of evidence presented here and on the fact that environmental conditions are thought to have an effect on the magnetosome mineral produced in these organisms (13). Although they differ morphologically, there are several similarities between the large rods and the greigite-producing MMP group. These obligately multicellular organisms consist of 10 to 60 genetically identical cells and are also phylogenetically affiliated with the Deltaproteobacteria class of the Proteobacteria phylum (9-11, 24). Some are known to biomineralize magnetite as well as greigite (25), and based on phylogenetic and genetic evidence, the MMPs appear to be anaerobic, sulfate-reducing bacteria (9-11, 24).

Recently, magnetosome (mam) genes, similar to those in magnetite-producing magnetotactic bacteria, have been found in an MMP that produced only greigite, leading to the idea that the magnetotactic trait, whether based on iron oxide or iron sulfide production, is monophyletic (26). The fact that magnetite and/or greigite production can be controlled in cells of a single species by modifying the external chemistry and redox potential suggests that there might be specific genes involved in greigite production in some large rods and MMPs that are expressed in certain conditions. We identified mam genes in the genome of strain BW-1 that are mostly present as two copies (table S2) and appear to form two separate clusters (fig. S5). The first cluster contains genes encoding for magnetosome proteins most closely related to those of the magnetite-producer Desulfovibrio magneticus strain RS-1 (27). The second cluster contains genes encoding for proteins most closely related to those of the greigite-producer Candidatus Magnetoglobus multicellularis (26). These results point to the possibility that different forms of mam genes are responsible for magnetite (cluster one) and greigite (cluster two) biomineralization (fig. S5) and that the two gene clusters are regulated differentially, resulting in different proportions of magnetite and greigite in cells.

\section{References and Notes}

1. R. B. Frankel, D. A. Bazylinski, Rev. Mineral. 54, 95 (2003).

2. D. A. Bazylinski, R. B. Frankel, Nat. Rev. Microbiol. 2, 217 (2004).

3. A. Komeili, Annu. Rev. Biochem. 76, 351 (2007).

4. D. Schüler, FEMS Microbiol. Rev. 32, 654 (2008)

5. S. Spring, D. A. Bazylinski, Prokaryotes 2, 842 (2006).

6. S. Mann, N. H. C. Sparks, R. B. Frankel, D. A. Bazylinski, H. W. Jannasch, Nature 343, 258 (1990).

7. M. Farina, D. Motta de Esquivel, H. G. P. Lins de Barros, Nature 343, 256 (1990).

8. S. L. Simmons, S. M. Sievert, R. B. Frankel, D. A. Bazylinski, K. ]. Edwards, Appl. Environ. Microbiol. 70, 6230 (2004).

9. F. Abreu et al., Int. J. Syst. Evol. Microbiol. 57, 1318 (2007).

10. S. L. Simmons, K. ]. Edwards, Environ. Microbiol. 9, 206 (2007).

11. R. Wenter, G. Wanner, D. Schüler, ]. Overmann, Environ. Microbiol. 11, 1493 (2009).

12. D. A. Bazylinski, B. R. Heywood, S. Mann, R. B. Frankel, Nature 366, 218 (1993).

13. D. A. Bazylinski et al., Appl. Environ. Microbiol. 61, 3232 (1995).

14. T. Kasama et al., Am. Mineral. 91, 1216 (2006). 
15. R. Amann, J. Peplies, D. Schüler, in Magnetoreception and Magnetosomes in Bacteria, D. Schüler, Ed. (Springer-Verlag, Berlin Heidelberg, 2007), pp. 25-36.

16. Materials and methods are available as supporting material on Science Online.

17. D. Schüler, Int. Microbiol. 5, 209 (2002).

18. C. T. Lefèvre et al., ISME J., published online 21 July 2011 (10.1038/ismej.2011.97).

19. R. S. Wolfe, R. K. Thauer, N. Pfennig, FEMS Microbiol. Lett. 45, 31 (1987)

20. C. T. Lefèvre et al., Earth Planet. Sci. Lett. 312, 194 (2011).

21. D. J. Lane, in Nucleic Acid Techniques in Bacterial Systematics, E. Stackebrandt, M. Goodfellow, Eds. (Wiley, Chichester, 1991), pp. 115-175.

22. W. Manz, R. Amann, W. Ludwig, M. Wagner, K.-H. Schleifer, Syst. Appl. Microbiol. 15, 593 (1992).

23. F. P. Abreu, K. T. Silva, M. Farina, C. N. Keim, U. Lins, Int. Microbiol. 11, 75 (2008).

24. E. F. DeLong, R. B. Frankel, D. A. Bazylinski, Science 259, 803 (1993).

25. U. Lins, C. N. Keim, F. F. Evans, P. R. Buseck, M. Farina, Geomicrobiol. J. 24, 43 (2007)
26. F. Abreu et al., ISME J. 5, 1634 (2011).

27. H. Nakazawa et al., Genome Res. 19, 1801 (2009).

28. C. T. Lefèvre et al., Appl. Environ. Microbiol. 76, 3740 (2010).

29. C. T. Lefèvre, R. B. Frankel, F. Abreu, U. Lins, D. A. Bazylinski, Environ. Microbiol. 13, 538 (2011).

Acknowledgments: This work was partially supported by U.S. National Science Foundation grant EAR-0920718 (D.A.B.) and by a grant from the Fondation pour la Recherche Médicale SPF20101220993 (C.T.L.). Part of the transmission electron microscopy characterization was carried out in Ames Lab and was supported by the U.S. Department of Energy, Basic Energy Sciences, Materials Sciences and Engineering Division. The Ames Laboratory is operated for the U.S. Department of Energy by lowa State University under contract DE-AC02-07CH11358. We thank F. Mahlaoui and M. L. Schmidt for help with sampling; the National Park Service staff of Death Valley National Park; and the team at the Laboratório de Bioinformática, Laboratório Nacional de Computação Científica, Rio de Janeiro, Brazil, for their help in the sequencing and annotation of the genome of strain BW-1. Samples at Death Valley National Park were collected under Sampling Permit DEVA-2010-SCI-0038 issued by the U.S. Department of the Interior National Park Service. 16S rRNA gene sequences (accession nos. JN015483 to JN015507, JN252194, and JN25219), gene for adenosine-5'-phosphate reductase (aprA; JN705544) and mam genes of BW-1 (JN830627 to ]N830646 and JN845570 to JN845575) are published in GenBank. Strain BW-1 has been deposited to the Japan Collection of Microorganisms, RIKEN BioResource Center under the provisional name Candidatus Desulfamplus magnetomortis and carries accession no. JCM 18010.

\section{Supporting Online Material}

www.sciencemag.org/cgi/content/full/334/6063/1720/DC1

Materials and Methods

SOM Text

Figs. $\mathrm{S} 1$ to $\mathrm{S} 6$

Tables S1 and S2

References (30-39)

Movies S1 and S2

12 August 2011; accepted 2 November 2011

10.1126/science.1212596 